\title{
Innovation and systems for economizing the production of energetic comfort
}

\author{
Maria-Alexandra $\operatorname{Ivan}^{*}$ \\ The Hague University, Johanna Westerdijkplein 75, 2521 EN Den Haag, Netherlands
}

\begin{abstract}
The buildings evolution for economic entities in terms of energy requires substantive changes in the designs equipment system components that are able to create comfort in these conditions. Nowadays, the technology gives the opportunity of creating compact and efficient systems. The devices for high power heat exchangers have incredible small sizes and insane designs in comparison with those from 30 to 50 years ago. A future scenario would be that the investment value of buildings would be accomplished by $50 \%$ for the construction itself and $50 \%$ for the devices that give comfort. The high volume of devices created for offering high quality comfort demands a new design for these type of devices - especially as those gadgets will be placed in plain sight, their design must be adapted for the new functions. This outlines that most of them would have the goal of giving the function of a piece of furniture or even decorative pieces. The future designer stands in front of a new challenge, as its creation of such devices will demand to offer comfort to the occupants and the functionality of the devices. This research analyzes innovative future scenarios and solutions that could be adopted by designers.
\end{abstract}

\section{New technologically advanced buildings and innovation}

Unlike the older buildings, nowadays the new and innovative buildings require the application of technological solutions designed for achieving thermal, visual and lighting comfort, but also protecting the residents from noise. For that, a technological system is being uniquely created for every request.

By tracking the parameters of all types of comfort it increasingly tends to be automated through the BMS (Building Management System) that also serve to adjust their command. If the value of investment for technological comfort was in the past up to $15-20 \%$ out of the value of the building, now the complex systems serving comfort, reach $50 \%$ of the total investment. In this situation researchers have called the modern house, the technologically advanced house. In this case, innovation has an important role [1]. The importance of innovation in these situations refers to changing and creating more effective processes and systems. By that, innovation introduces thoughtful application of information, imagination and initiative in acquiring better or distinctive values from resources. Being innovative does not mean inventing, but changing processes and systems by adapting to the environment to deliver the required conditions and preferences of the user.

\footnotetext{
* e-mail: ivanmariaalexandra@gmail.com
}

\section{Appling innovation to achieve new shapes for a more pleasant design - hidden systems in furniture}

Air conditioners are considered units of comfort that most homeowners use with the ease of flipping a switch, but in fact they are complicated electromechanical systems. As simple as it seems and easy to use, these systems are the end result of almost a century of engineering development and innovation in thermodynamics, energy efficiency and cooling.

Benjamin Franklin [2], the American inventor and statesman was intrigued by the concept of air-cooling, so in 1758 started experimenting with evaporation of alcohol to attain freezing temperatures. Although, Willis Havilland Carrier was the one who created the very first system of air conditioning. He started the concept by experimenting with the laws of humidity control so that he could solve an application problem at a printing plant in Brooklyn, New York. Nowadays systems are still working under the equivalent fundamental science like Carrier's 1933 system, but with the included advancements for diagnostic and control, vapor compression, electronic sensors, materials and energy efficiency.

Since then, the systems for cooling and heating the air temperature in houses have been put through adjustments and development. Innovation has played an important role in the improvements that were made regarding these systems. To consider, as previously stated, innovation does 
not equal inventing necessarily. By taking these systems as an example, the original invention has been developed more and more until it reached the point of a cluster of systems customized according to the user's requirements and preferences.

Nevertheless, analyzing the systems that can be found at this moment on the market, we can see the differences in size and design referring to shapes, colors, materials, etc. By implementing innovation to achieve the user's requirements, these systems have gone through thorough modifications and analysis [3]. Using innovation in such a way it can last for years till the final product is ready for producing. It may not seem true, but innovation is not as simple as adding to something, or making another curve in the design section so that the system can be found on the market. One of the very first steps that must be taken into account when starting an innovation project is stating the problem. Finding out what is inconvenient or what the problem is, a design goal and vision can be created afterwards so you could know what the end results should look like. Subsequently, a research phase starts and within this phase, the user's requirements are being taken into account. Using the results from the research phase, the next step can start, which is designing.

When proceeding with this phase, the user's preferences are being applied. Everything that is being done during this phase can be seen at the very end of the project, when basically the concept turns into a product, service or system. That is the moment when the user's preferences can be seen taken into account or not. Normally, every product, service or system that has gone through an innovative project cannot be produced if the requirements are not being accomplished. Going back to the systems, over the years, lots of developments have been accomplished, from the engineering field to design. Lately it has been observed that users do not consider whether the engineering part can or not be done, but their interest has focused on the design of the systems. Most of the people started being concerned about the limited space that they have in their home. Due to that, designers started to develop systems that would make the users happy. For that a lot of innovative ideas have been brought up. These ideas refer to designing systems that would be able to be placed in smaller spaces and blend with the surroundings to achieve the owner's preferences.

Because of the user's demands, the engineers had to reconsider the systems and develop it more compact but also more economic [4]. As the technology has increased in its development, crazier and never before thought of designs, shapes, colors have appeared on the market compared to the ones from 10 to 20 years ago.

\section{Appling innovation to reduce system dimensions and to increase its elegance and fineness}

Technology has developed throughout the years with the help of innovation in order to create comfort for the users. As time has passed by it has been observed what people's problems are in the confines of their houses.
To help them and to give them the comfort needed, research has been made during innovation processes. Through research, the technology has reached a level where it is being created for certain types of houses, for a certain category of people, but also for diseases that people suffer from. Presently, the technology has created customized devices so users can have the final decision when it comes to their comfort [5]. For innovators, this was not enough, so they looked into designing and creating not only comfort but also a beautiful scene for the users in their homes. Meaning that after deciding on their needs, they can create an interface according to their personality, wants and likes. In this way, they can accomplish a mix between a technological comfort and modern decorative design for those systems. Each person decorates their living space by what beautiful means to them, innovation taking form by hiding and blending itself with its surroundings. Still, during all these processes, rules and regulations have been strictly monitored and respected to achieve comfort norms. These norms concerning the parameters of comfort refer to interior temperature, relative humidity, interior light and the noise level. Each system has been created for a specific activity, destination and environment that suit the entire people that live in that building [6].

Considering everything previously stated, these are a few examples of what innovation has created for people's comfort:

In Figure 1 the air conditioner has been blended into its surroundings through shape, size, color, at the same time remaining normatively efficient [7].

Figure 2 represents another air conditioner [8], but this time infused with the furniture itself, hiding its presence through a slick and fine design while staying perfectly functional.

In the upcoming picture (Fig. 3), the air conditioner is placed above on one of the decorative shelves. The product was considered as decorative object but not as an industrial device (Fig. 4) [9].

The following image shows a ventilation grille which aspect was modified in order to create a pleasant design to make people experience a certain atmosphere, the one that can be found in the specific environment [10].

In Figure 5 the ventilation shaft has been customized so that it can continue serving its purpose to cool and heat the bottom circulating air while maintaining a pleasant, nonintrusive design [11].

\section{Innovation applied in the renewable energy systems}

Over the years, renewable energy systems have gone through an increasing path and developments from the technological part till people's awareness about this field. These types of systems were very little known by individuals, more by the ones in the specialized field.

Over time, the renewable subject has spread over the world and people have started to find out about it. If at the beginning people were sceptical with regards to this subject, nowadays they have started to understand the benefits that people can gain from. The subject at hand is 


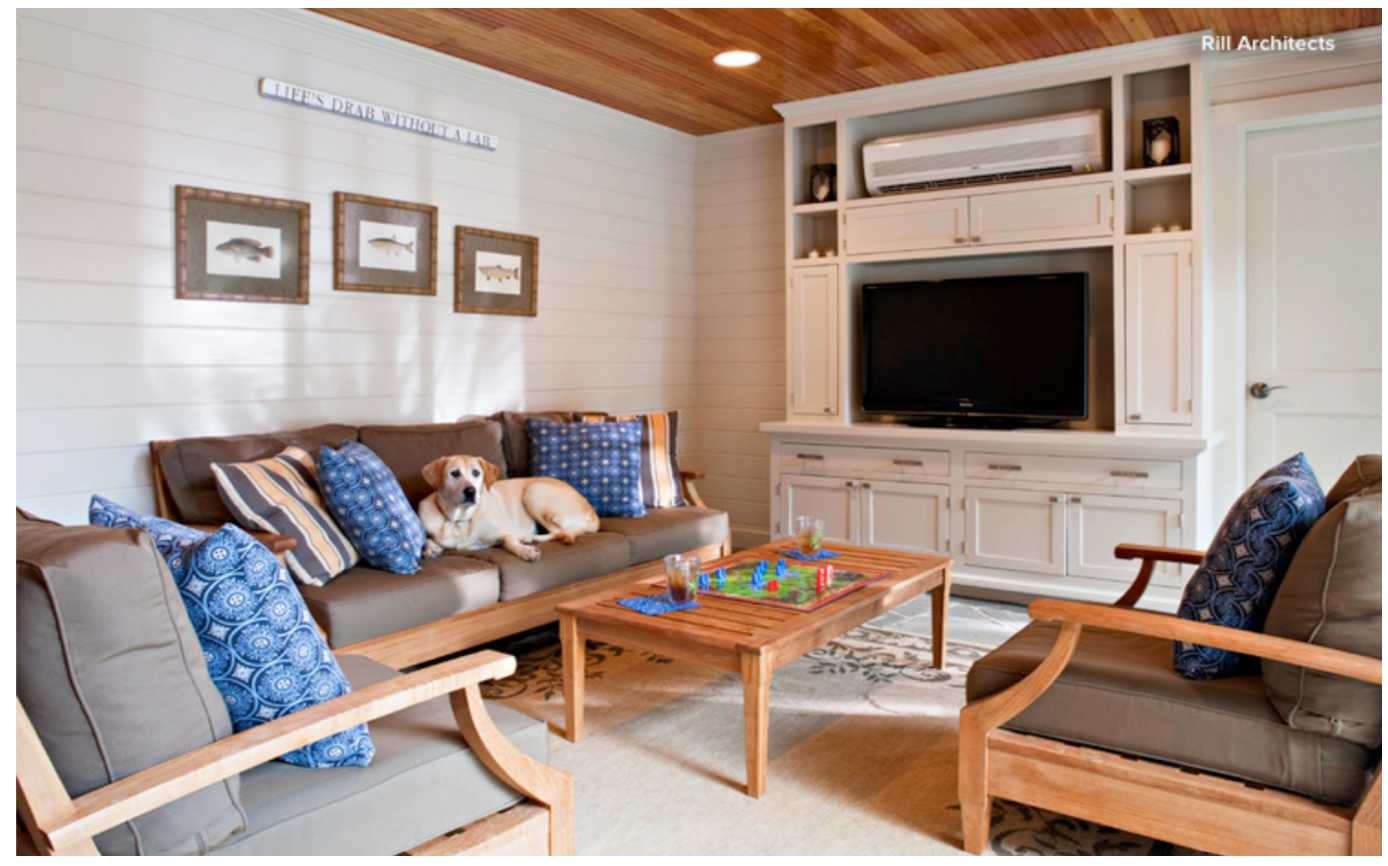

Fig. 1. Air conditioner placed into furniture.
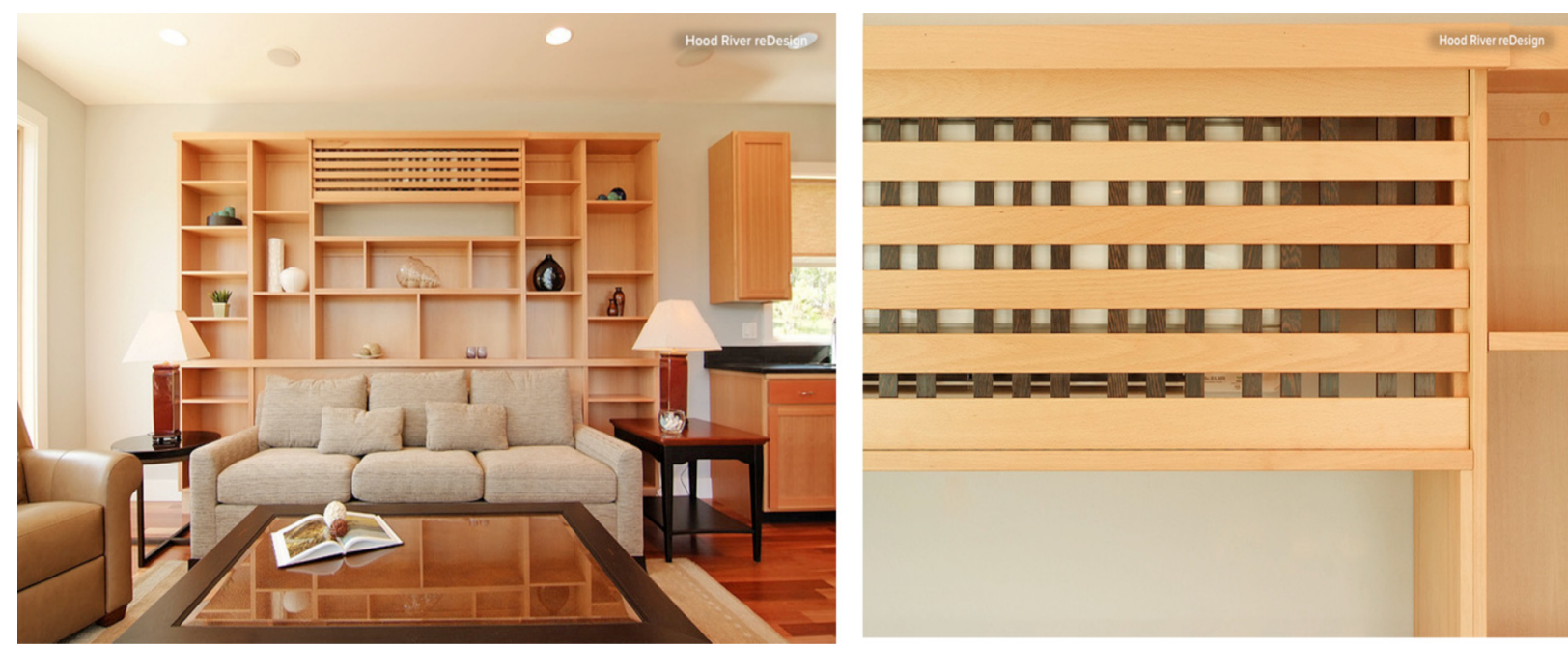

Fig. 2. Air conditioner hidden in the furniture.

passing more and more to young people which day by day come up with unique and creative ideas, at the same time providing solutions to thus known as impossible borders. We are experiencing an age in which the attention is focused more on solving challenges that lead to advancements in the field. Design and innovation are becoming major criteria to take in perspective along with architecture, advances in technology, new construction materials and so on and so forth.

One of the major problems our world is struggling to solve concerns energy. Renewable or clean energy is believed to be the future. As previously stated innovation and design will have a major influence. This type of energy has been reduced to local and household usage and also increased to a huge, industrial scale. For example, many homes situated in highwind areas use miniaturized versions of wind turbines to provide themselves with free energy. Scaling this idea to a town sized population it has already been proven sustainable. Further increasing the scale to global size, I personally think that a future scenario will look like this: every household, farm, school, hospital, factory and so on, will be able to sustain themselves. Everything stated would transform into chaos if we would not take into account a proportional growth from a personal house to an urban settlement to a city and further, at the same time considering the industry. All of these, need to be in perfect sync with one another, and optimized properly so there is no waste of energy, to be able to grow in size. 


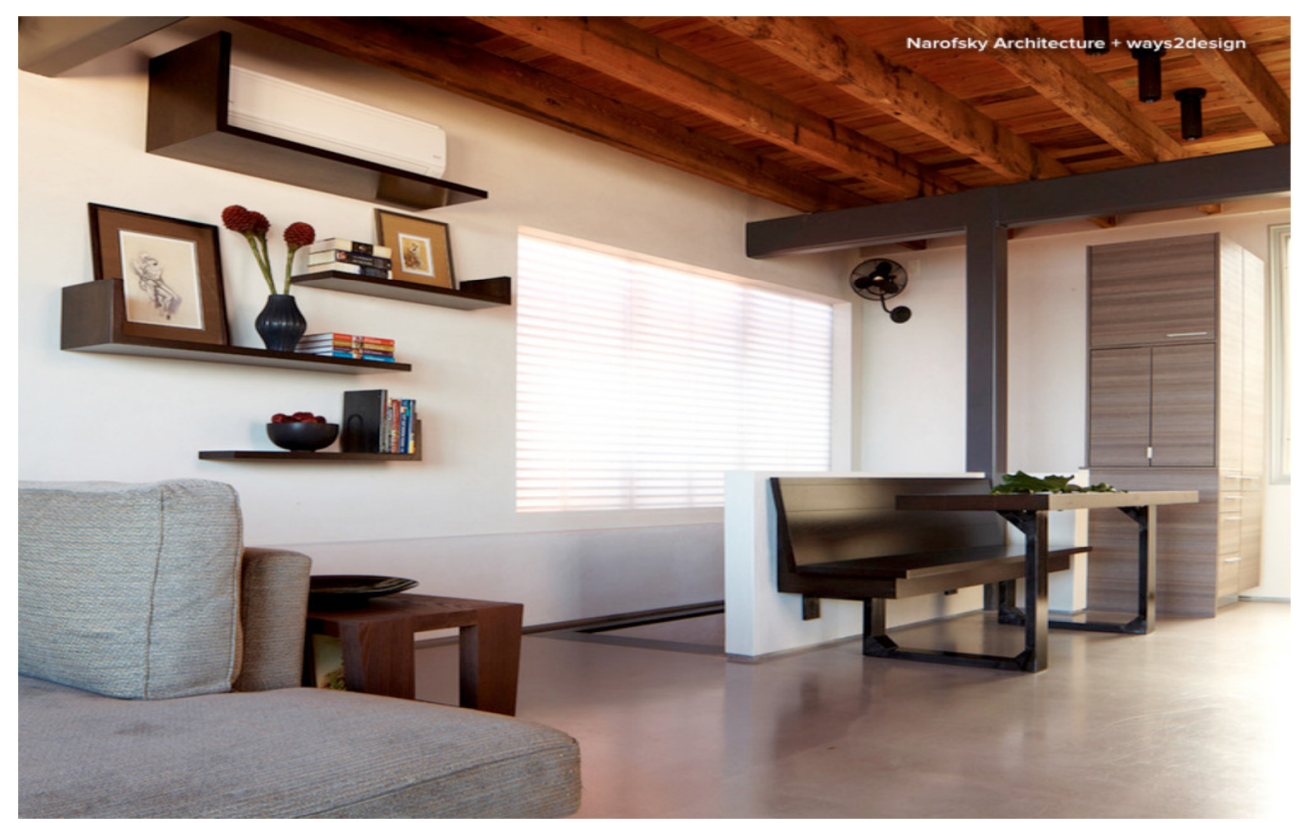

Fig. 3. Air conditioner integrated as a decorative object.
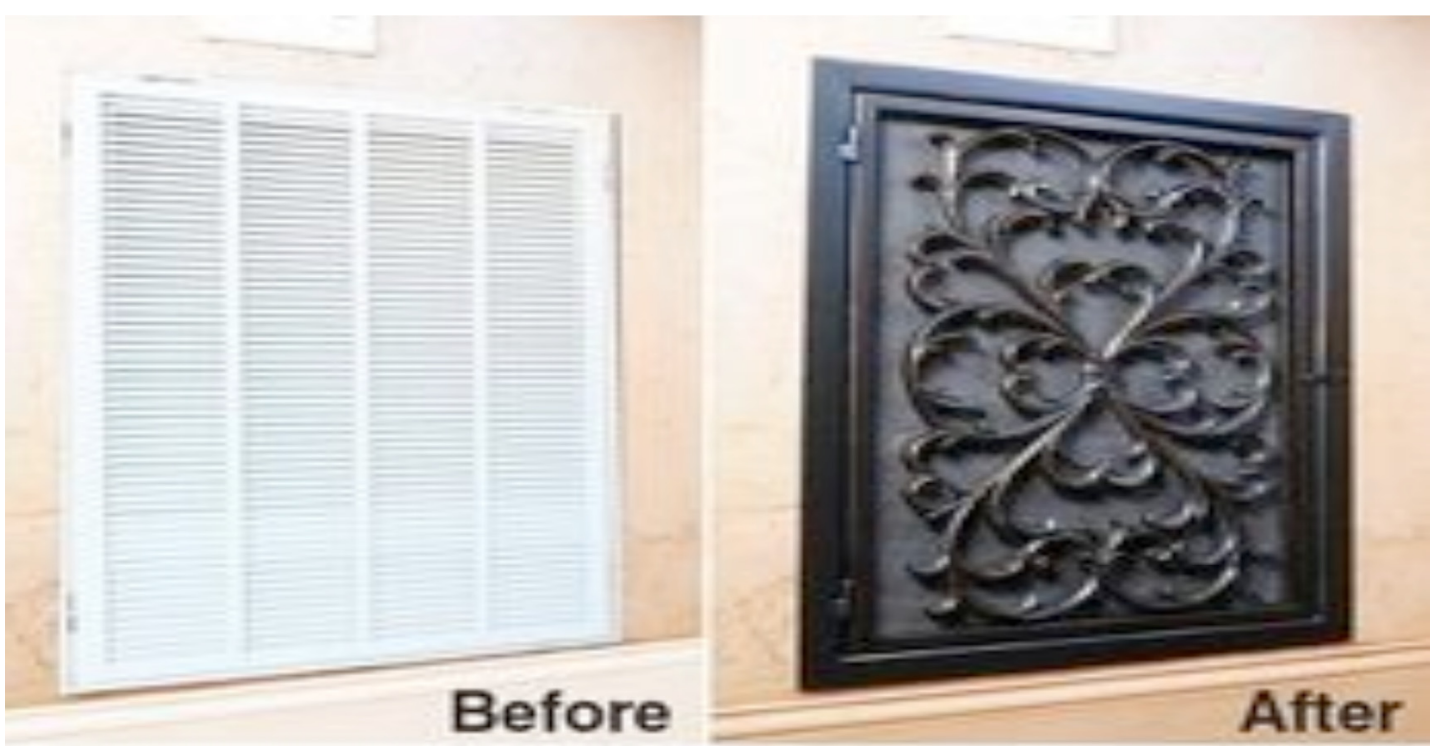

Fig. 4. Ventilation grille with new design.

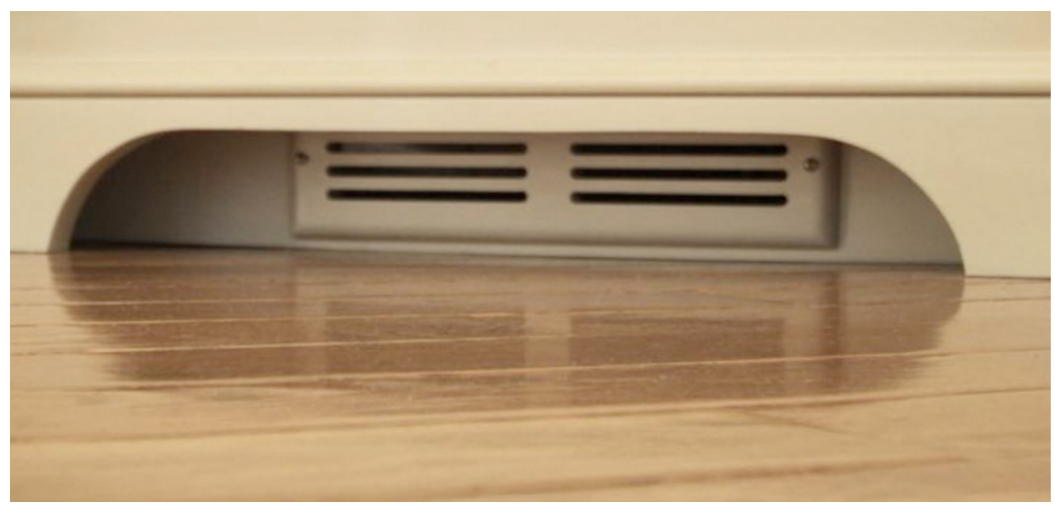

Fig. 5. Ventilation main handrail with special design. 


\section{Conclusions}

The innovative design creates the interior, sometimes even part of the exterior of buildings, like the ledge, from an industrial aspect into a personal one. For that, people specialized in design need to combine their knowledge with advances in technology, so that the system's performance will increase. Moreover, there should always be taken into account: the owner's preferences regarding space, finish, certain design specifics, etc.

The innovative design is a field with big appliances in the technological future that can be found everywhere. As previously stated, a future scenario will include every human settlement as becoming self-sustainable, but what about every piece of machinery that we have and also will further create?

I wonder if we will be able to even harness the movement of tectonic plates as a method to create energy.

How can we develop a form of free energy that we can use in practically everything without special needs of: wind, water, solar power, and so on, to maybe (and this is a radical idea) conquer the unknown, thus pushing the boundaries of our own world?

\section{References}

1. G. Ivan, Economical and ecological production of heat and cold (Instalatorul, 2002), Vol. 5

2. E. Palermo, Who invented air conditioning?, http://www. livescience.com/45268-who-invented-air-conditioning.html

3. G. Ivan, Heat exchangers for modern cooling plants, Instalatorul 7, (1997)

4. R. Crutescu, G. Ivan, Pollution reduction by implementing the passive house concept, in Stiinta Moderna si Energia, in SME 2012, Cluj 17-18 Mai 2012, 2012, p. 224

5. R. Valkenburg, J. Sluijs, The world of the open innovator (The Hague University of Applied Science, The Hague, The Netherlands, 2012)

6. G. Ivan, Special compact exchangers for passive houses, Technical Bulletins of Debrecen Debreceni Múszaki Közlemenyek 10, 2 (2010)

7. https://www.pinterest.com/pin/137570963593888614/

8. http://www.houzz.com/ideabooks/29446243/list/10-waysto-hide-that-air-conditioner

9. http://modernize.com/hvac/cooling

10. https://www.pinterest.com/explore/air-vent/

11. https://www.pinterest.com/mymziemullins/central-air-acunit/

Cite this article as: Maria-Alexandra Ivan, Innovation and systems for economizing the production of energetic comfort, Renew. Energy Environ. Sustain. 1, 14 (2016) 